\title{
Oscar Wilde as a Temporal Designer: A Case Study of The Picture of Dorian Gray
}

\author{
Bahram Behin \\ Department of English - Azarbaijan Shahid Madani University \\ Tabriz - Iran \\ E-mail: bahram.behin@gmail.com \\ Mahdiyeh T. Khiabani (Corresponding author) \\ Department of English - Azarbaijan Shahid Madani University \\ Tabriz - Iran \\ E-mail: Mahdiyeh.tabaghchikhiabani@ugent.be
}

Received: 05-09-2014

Accepted: 06-11-2014

Published: 01-03-2015

doi:10.7575/aiac.ijalel.v.4n.2p.199

URL: http://dx.doi.org/10.7575/aiac.ijalel.v.4n.2p.199

\begin{abstract}
Since the publication of Oscar Wilde's The Picture of Dorian Gray, there have been great amounts of ideological criticism both for and against the author and the work. Critics have variously evaluated the work from different perspectives; however, these studies have largely targeted the thematic aspects of the novel, while little serious attempt has been made to examine the narrativity of this great work. As a result, the narrative structure of this novel still remains quite untouched. As a partial fulfillment, the present paper has examined the temporal structure of the novel. The analysis indicated that temporality is one of the very functional elements of the work. In fact, much of the meaning or the effect the author intends to converse through each action, character, or dialogue is firstly embedded in a proper and effective temporal setting. Moreover, the analysis ascertained that the well-set temporal structure of the work has resulted in (1) Ekphrasis, (2) Characterization, and (3) Reader manipulation. According to the paper, these three elements dramatically carry out the influentiality of this great novel.
\end{abstract}

Keywords: temporality, narratology, textual analysis

\section{Introduction}

The literature review shows that there has still been a large interest in the themes, implications of The Picture of Dorian Gray, and its associations with the author and his personal life. A number of critical readings of the novel are attributed to the notions of aestheticism, ethics, and hedonism (e.g. Gillespie, 1995; Manganiello, 1983;) ; a much wider number of studies have been tracing Wilde, his desires, and life style within the novel as a kind of implied autobiography (e.g. Nethercot, 1944; Baker, 1969; Oates, 1980; Danson, 1991; Lane, 1994; Leckrone, 1999; Adu, 2005; Snider, 2009). furthermore, a more recent attention is devoted to the study of National considerations (e.g. Mirzoeff, 1988; Gillespie, 1994; Melmoth, 2000; Stetz, 2001; Walshe, 2005;). However, in studies on this great novel there have been less serious studies to analyze this influential novel from a narratological perspective. While the history of the critical readings of this work is in search of attributing the success of the novel to its ideology, this study proposes a methodological approach through a temporal investigation aiming to analyze the structure of the novel as a narrative; this can open a new gate towards the success and the influence of the novel. To do so, the concept of temporality is applied to the novel in order to demonstrate the explicit and implicit temporal techniques within it, in regards to their significant roles and functions in the narrativity of the novel.

\subsection{Tracing Temporality in The Picture of Dorian Gray}

In its classical sense, time in narrative refers to a specific date, ranging from a day to years probably. Although such an assumption of time has relatively lost its significance for the sake of much newer definitions of narrative temporality, it still stands a remarkable aspect in the analysis of narratives for at least one important issue. The date of a narrative usually acts as a content-revealing element in narrativity. For instance, what 1939 implies significantly differs from what 1945 might do; while the first implies the misery of the coming bloody war, the second may indicate an attempt to revive and reconstruct. The setting of a dark winter evening does not imply what a spring morning indicates. Happy lovers rarely meet in a stormy black autumn evening, and one may never normally read of a bloody death happening in a spring noon when birds are singing the song of liveliness everywhere, unless they trigger specific implications with such contradictions between the setting and the action of a narrative.

The Picture of Dorian Gray opens with a long remarkable description of a shiny day, the time of the "odour of roses", with the "shadows of birds" ( $\left.C W^{l} 169\right)$ creating a fantastic imagery for the reader. The selection of the temporal setting,

\footnotetext{
${ }^{1}$ The Complete Works of Oscar Wilde
} 
and the shining sun above the trees of the garden cannot be a random choice in the narrative of the novel; the selected time is a very adroit choice for staging the three main characters of the novel who are initially aimed to look attractive, fascinating, and gorgeous; the selection of the time of the season and the day significantly presupposes shiny and elevated characters as well embedded in a proper selection of time, completely in accordance with what the reader is intended to characterize in his personal world. When the novel starts, the readers construct a mental image of the three characters that are, automatically, as elevated, fantastic, and luxurious as the time selected for their portrayal as a shiny fresh day. Chapter XII starts with an exact date of "the ninth of November, the eve of his [Dorian's] own thirty-eighth birthday" (CW 291), with a description of a foggy, cold night, around 11 o'clock, when Dorian, coming home from Lord Henry's house, sees Basil Hallward after a long time, and is forced to let him in where Basil's horrible murder takes place. Unlike the temporal setting of chapter I, with the staging of the three charming characters in a sunny fantastic day light, in this chapter, with the death of Basil as its most important event, the given setting is completely compatible with the event which is undoubtedly shocking to the reader.

The signification of temporal setting as an embedment for what is to be revealed in each event is completely discernable in these two examples just mentioned. In fact, in chapter I, the reader is impressed by a vivid, delighting, and appealing temporal charm, since he is meant to be absorbed in the elegance of the three characters (especially Lord Henry and Dorian); however, in chapter XII the temporal setting stands as a warning point which (un)consciously pushes the reader towards the coldness and wilderness of the night, since the reader is to move towards a horrifying revelation of Dorian's true nature, where wilderness and coldness of the temporal setting is connected to the wilderness of a nature within a man who is a charming considerable hero for the reader in some earlier chapters.

The case of Dorian's love to Sibyl Vane is another noteworthy example. It was noted above that normally there is compatibility between the selection of time and the incident taking place within it; such compatibility is rarely violated, unless there is significance in such a violation, which carries a meaning, in fact. The lines describing the setting before Dorian meets Sibyl in the theatre are instances of such violation:

I [Dorian says] don't know what I expected, but I went out and wandered eastward, soon losing my way in a labyrinth of grimy streets and black grassless squares. About half-past eight I passed by an absurd little theatre, with great flaring gas-jets and gaudy play-bills. A hideous Jew, in the most amazing waistcoat I ever beheld in my life, was standing at the entrance, smoking a vile cigar. He had greasy ringlets, and an enormous diamond blazed in the centre of a soiled shirt. 'Have a box, my Lord?' ( $C W 211)$.

The reader might have been surprised at, or simply put in an uneasy feeling towards setting a "sacred love" in "grimy streets", and the "absurd little theatre" as a violation of setting and the action; however, passing on the process of the narrative, s/he realizes that no such 'venerability' exists in Dorian's feelings towards this innocent actress and the so called "sacred love". In this case, through the selection of a specific time (night) the reader is initially put in a possibly unaware conflicting combination of time and action, which later turns out to be a revelation of a 'dark' desire camouflaged as love, which stands in line with the darkness of the setting.

In addition to the traditional consideration of temporality, Genette proposed a more systematic analysis of temporality in literary works. He identified three dimensions in this realm, namely, order, frequency, and duration. Order determines in what sequence the events are presented at the narrative level in comparison to their actual order at the story level. Frequency testifies "the numerical relationship between the events" (Bal, 111) at story and narrative levels. Duration deals with the length of each action or event at both levels and how they stand to one another. Genette's assumptions were later expanded, modified, and clarified by many other scholars (e.g. Miek Bal, Monika Fludernik, Herman \& Vervaeck, etc.).

\subsubsection{Order}

As noted, order refers to the arrangement of events at both levels of story and narrative. Unlike various types of art forms like visual arts, "written linguistic text is linear", or in another term ordered in which words and sentences follow one another in double linearity: that of the narrative, "the series of sentences" and that of the story (Bal 81). According to Genette,

[t]o study the temporal order of a narrative is to compare the order in which events or temporal sections are arranged in the narrative discourse with the order of succession these same events or temporal segments have in the story, to the extent that story order is explicitly indicated by the narrative itself or infer-able from one or another indirect clue (35).

Keeping this double linearity in mind, three main types of order are distinguishable in a narrative, presented in figure 1.

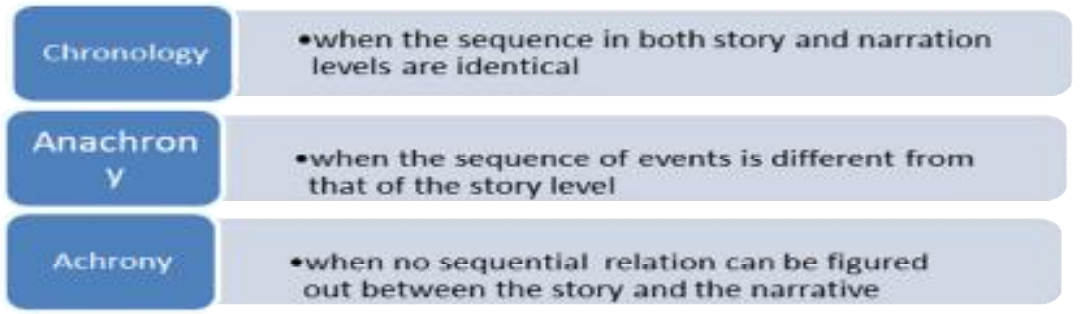

Figure 1. Types of order proposed by Gérard Genette (1980) 
The novel starts in medias res regarding the age of the hero whose story starts in the narrative from the middle of his life in which Dorian appears as a young man. It is noteworthy that the narrative exactly starts from the very point of his meeting Basil and Lord Henry, with the consequences of the wish about the painting, astonishingly coming true later. When the novel starts, the readers move on a step by step process in the narrative, in which events follow one another in their chronological order. The novel starts when Dorian is a young man, and proceeds in time to its final chapter where Dorian is a quite aged man. Despite minor references to some points temporally prior to the beginning of the narrative presented in flashback (discussed later), the novel enjoys an overall linearity in the narrative in a user -friendly method, which allows the reader to concentrate freely on the content of the narrative without effort. The ordering of the narrative provides the opportunity for the reader to follow the actions and thoughts in ease of mind and more focused.

\subsubsection{Frequency}

As another component of temporality, frequency discusses the number of times an event occurs at the story level compared to the number of times it occurs at the narrative level. Miek Bal classifies frequency as below:

\begin{tabular}{l|l}
\hline Singular & one event, one presentation \\
plurisingular & various events, various presentations \\
varisingular & various events, various presentations, unequal in number \\
repetitive & one event, various presentations \\
iterative & various events, one presentation
\end{tabular}

Figure 2. Frequency subcategories (adopted from Bal, 113)

Among the possible subcategories of frequency, the analysis indicated that repetitive mood has played the most significant role in the narrative of the novel. The first significant case where repetition occurs relates to Dorian's engagement to Sibyl. Definitely, Dorian's meeting Sibyl works as a turning point in the narrative. That might be the main reason for the repetition of this incident. She is unveiled to the reader in chapter IV, while Dorian is sitting at Lord Henry's luxurious house describing how madly he is in love with an actress whose name the world does not know yet. From his own fascinating yet poisonous viewpoint, as is his fashion, Lord Henry intends to look at Dorian's love case from an aesthetical and experiential view. What is "love" for Dorian is merely a "romance" for Lord Henry, which should not limit itself to one but many, providing one with newer feelings and sensations. The whole chapter stands as an argument between Lord Henry and Dorian about the romantic appreciation of women, love, and marriage in contrast to instrumental use of these notions for the sake of experience and curiosity. On the other hand, Basil knows about this 'love affair' in chapter VI, in which the love issue is being presented to the reader once more as a repetition at the narrative level. By this repetition, the reader is given the chance to reconsider the case, but this time through two diverse standpoints, one by Lord Henry and the other by Basil. For Lord Henry, love is but a mere charming play to be played with, to be acted upon, and to be wrapped up for the sake of a different one. Unlikely, the way Basil reacts to this incident shows how positively he defines love and women. The two chapters of IV and VI, as retellings of Dorian and Sibyl's love story, provide the reader not only with three divert viewpoints towards the important event of Dorian's love, but also it pushes the reader towards a reconsideration of the event which turns out to be fatal in Dorian's life.

The second repetition takes place when the news of Sibyl's death reaches Dorian. Chapters VIII and IX successively deal with the news reported to Dorian, first by Lord Henry in chapter VIII, and later by Basil in chapter IX, who does not know yet that Lord Henry has already washed the pains and sorrows of the tragic event away from Dorian's mind and heart. In chapter VIII, as Lord Henry reported the suicide news to Dorian, "[a] cry of pain broke from the lad's lips, and he leaped to his feet, tearing his hands away from Lord Henry's grasp. "Dead! Sibyl dead! It is not true! It is a horrible lie! How dare you say it?" [Says Dorian]" $(C W 251)$. This reaction stands completely compatible with the reader's expectations since Dorian wrote such an affectionate letter, asking her to forgive him the night before. But the surprising point is how in the middle of the pain of Sibyl's loss, Lord Henry invites Dorian to calm down, dine with him, and attend to a party in which his sister "has got some smart women with her" ( $C W$ 252). More surprisingly, influenced by Lord Henry, Dorian immediately creates a fictional tragic play out of this factual tragedy and in the next chapter (as a repetition of the same event), when Basil talks about the issue, the reader realizes that a new Dorian is born out of the story; the response he gives to Basil shows this radical change:

Stop, Basil! I won't hear it!" cried Dorian, leaping to his feet. "You must not tell me about things. What is done is done. What is past is past." "You call yesterday the past?" "What has the actual lapse of time got to do with it? It is only shallow people who require years to get rid of an emotion. A man who is master of himself can end a sorrow as easily as he can invent a pleasure. I don't want to be at the mercy of my emotions. I want to use them, to enjoy them, and to dominate them." "Dorian, this is horrible! Something has changed you completely. You look exactly the same wonderful boy who, day after day, used to come down to my studio to sit for his picture. But you were simple, natural, and affectionate then. You were the most unspoiled creature in the whole world. Now, I don't know what has come over you. You talk as if you had no heart, no pity in you. It is all Lord Henry's influence. I see that." ( $C W 97)$. 
The repetition of Sibyl's suicide in the two mentioned chapters gives the opportunity for the reader to reconsider the case from three different points of view again; for the first radical time s/he can distinguish the opposing worlds the lads are living in, especially considering Lord Henry and Basil on the two opposite poles, and Dorian blindly putting Lord Henry's theories into practice and even calling himself in debt to him for teaching the philosophy of life and love. Chapter VIII and IX located at the middle of the novel exactly sharpen the reader's attention to the diverse standpoints of the two sides of evil (Lord Henry) and goodness (Basil) from which Dorian chooses the former. From these two chapters on, the narrative reveals an overt evil nature of Dorian who has no likeliness to the young man the reader has already created in mind as a childlike innocent and pure creature.

The created clashes, conflicts, and the divert roads of heaven and hell have successfully been depicted through the three characters who reveal their discernment of the world and its happenings within these repetitive chapters. Using a repetitive mood of frequency both for loving Sibyl and for her suicide indicates Wilde's conscious selection of frequency who knew how to play and shatter the reader's mentality towards the three characters, who, moving towards the middle of the narrative, turn out to be radically different from what they initially seemed to be. Dorian, taken as a true and innocent lover, proves to be a role player; the fascinating nature of Lord Henry Wotton changes to be "dreadfully demoralizing". The revelation of true natures is achieved by letting the three characters speak their minds about the striking story of Sibyl's love and suicide through the repetition of both incidents allowing each one of them to consider the issue from their own standpoint.

\subsubsection{Duration}

Regarding duration, naturally "the events themselves happen during a certain period of time" (Bal 208); shooting simply takes less than a second; giving birth to a baby probably takes a day long, while imprisonment can even take more than 20 years, or can even be lifelong. It deals with the duration of events at the story level compared to that of the narrative; there might be a compatibility of duration between these two levels, or they might prove discrepancies. Figure 3 shows the different types of duration.

\begin{tabular}{|l|l|l|l|}
\hline $\begin{array}{l}\text { Types of } \\
\text { duration }\end{array}$ & $\begin{array}{l}\text { Time of narration } \\
(\text { NT })\end{array}$ & Mathematic signs & $\begin{array}{l}\text { Story time } \\
(\text { ST })\end{array}$ \\
\hline Ellipsis & Narration stops & $(\mathrm{NT}=) 0<\mathrm{n}(=\mathrm{ST})$ & Action continues \\
\hline Summary & Narration & $(\mathrm{NT})<(\mathrm{ST})$ & Action \\
\hline Scene & Narration & $(\mathrm{NT}) \approx(\mathrm{ST})$ & Action \\
\hline Slow-down & Narration & $(\mathrm{NT})>(\mathrm{ST})$ & Action \\
\hline Pause & Narration continues & $(\mathrm{NT}=) \mathrm{n}>0(=\mathrm{ST})$ & Action stops \\
\hline
\end{tabular}

Figure 3. Durational patterns (Fludernik, 2009:34)

The Picture of Dorian Gray, like any other narrative has inevitably adopted various types of duration; due to space limits, I concisely deal with the most important events and demonstrate how the selected duration for each event has created a desirable effect in the course of the novel and the readers' understanding of them.

Ellipsis: Starting in medias res, the novel elides the background information about the hero's childhood, and the reader is directly introduced to a young man whose wealth and beauty stands as two defining keys and turn this hero to an amicable character. The ellipsis takes place for about 20 years of the hero's life, and his childhood is absent from the narrative level altogether; consequently, having no access to Dorian's background, the reader is forced to create an imaginary childhood for this character; naturally, since young Dorian is a wealthy attractive man, the presupposed childhood is also wealthy, luxurious and prince-like. However, a few chapters later in a flashback mood, the reader is hinted about the past, when Dorian was detested by his late grandfather. The flashback occurs through the descriptions and narrations given to the reader, while Dorian is entering his study room after years and remembers how painful and problematic his life was when living there. The depicted childhood, which stands completely different from what the reader presupposes, opens a new gate to the hero's gloomy past that has just stood as a perfect hero up to the very moment of opening the door of his study after years. Here, the reader finds out the weaknesses, the complexes, and the miseries that have been hidden from her/him through a deliberate selection of a specific mood of duration by which s/he would be put in specific untrue assumptions about Dorian.

Definitely, the very aim of the novel is to introduce a young, innocent, and perfect man to the reader, who remains so to the middle of the novel, while in the second phase of it, $\mathrm{s} /$ he faces a character who is neither perfect nor appreciable; the hero changes to an antiheroic character selling morality for an eternal youth. The greatness of the novel lies in the paradox it successfully creates in the reader towards two radically different emotions of love and hate towards Dorian as a "disposition of indeterminacy that runs throughout the narrative of The Picture of Dorian Gray" (Gillespie 2007, 388); such indeterminacy partially owes itself to the elided background.

Pause: Temporal analysis indicated that the novel introduces its characters after a pause; within the pause, the narrative describes a very fascination scenery, in which "the odour of roses", "the light summer wind", "heavy scent of lilacs", 
and the "delicate perfume of the pink-flowering thorn" ( $C W$ 169) have already occupied the reader's mind; it takes a pause of about 30 lines, to reach the names of two main characters, and a passing point at the third character as the 'hero' of the novel. The use of pause allows the narrator to apply his favored context for embedding a particular attitude in the reader. In this paragraph, through pause, the narrator grasps the chance of elaborating on a luxurious setting that implants a sense of supposing three characters of high importance, value, and social class in the reader. A 'Lord Henry Wotton' who is lying on "Persian saddle-bags" in a room where "now and then the fantastic shadows of birds in flight flitted across the long tussore-silk curtains that were stretched in front of the huge window, producing a kind of momentary Japanese effect" (Ibid) must definitely be a worthy man to read about. This durational type is not simply limited to chapter I of the novel; various chapters start with a mood of pause, in which relatively detailed descriptions are presented to the reader, prior to the exposition of the story, each one containing one purposeful temporal content and working as an external guide to the event embedded in it.

Slow-down: The fatal meeting of Basil and Dorian is depicted in the mood of slow-down. It takes several sentences to read about how their eyes met, and how Basil felt at the time. Acquainting with Basil entails fatal changes for both Dorian due to the portrait painted by Basil, and for Basil due to his feelings towards Dorian and his murder; also, the friendship provides an opportunity for Lord Henry Wotton to put his poisonous theories into practice. The most suitable temporal mood for such a fatal moment is but slow-down. The reading speed is adroitly decreased by numerous descriptions Basil adds to the scene of their first meeting,

Well, after I had been in the room about ten minutes, talking to huge overdressed dowagers and tedious academicians, I suddenly became conscious that someone was looking at me. I turned half-way round and saw Dorian Gray for the first time. When our eyes met, I felt that I was growing pale. A curious sensation of terror came over me. I knew that I had come face to face with someone whose mere personality was so fascinating that, if I allowed it to do so, it would absorb my whole nature, my whole soul, my very art itself. I did not want any external influence in my life. You know yourself, Lord Henry, how independent I am by nature. I have always been my own master; had at least always been so, till I met Dorian Gray. Then - but I don't know how to explain it to you. Something seemed to tell me that I was on the verge of a terrible crisis in my life. I had a strange feeling that fate had in store for me exquisite joys and exquisite sorrows. I grew afraid and turned to quit the room. It was not conscience that made me do so: it was a sort of cowardice. I take no credit to myself for trying to escape [Basil says] ( $C W 173)$.

As the paragraph shows, not only slow-down has occurred in the narration of the first meeting, but also, a type of pause is also identifiable towards the end of the paragraph, where Basil cuts the story and refers to his personality features. Slowdown and pause suggest the opportunity of creating suspense in this case, since the feelings Basil experiences at the moment of their meeting eyes seem a contradictory mixture of joy and sorrow, terrible crisis, fascinating personality, etc. Slowdown has employed a kind of foreshadowing of a contradiction the reader would face throughout the novel. In fact, what Basil experiences at this crucial moment, foreshadows what the reader is to carry with her/him even to the very moment of Dorian's death, the dilemma of who Lord Henry, Dorian, and even Basil are regarding the their true personality.

Scene: Not long after the three characters' befriending, chapter IV opens with Dorian at Lord Henry's house waiting for him to show up. As Lord Henry arrives, Dorian reveals his love of Sibyl to Lord Henry, in the form of a long dialogue, which covers almost the whole chapter in which Lord Henry and Dorian engage in a debate on love and women. The chapter stands crucial in the course of the novel since it covers Dorian's first independent decision for his life trying to construct his future through choosing Sibyl as his future wife; moreover, his devotion to love is also presented in this chapter. Later on, the course of the novel alerts the reader that chapter IV was not only a love basis for the hero of the novel, but also it was astonishingly the corruption point for Dorian. Due to his cruelty towards Sibyl, she commits suicide and to the reader's surprise, Dorian realizes that his sins seal themselves on the portrait rather than his face.

Since dialogue is central to scene, the chapter is a good depiction of scene in which the reader experiences a real-life time duration between what $\mathrm{s} / \mathrm{he}$ reads and what takes places between Lord Henry and Dorian at the story level. According to the analysis, the use of scene as the dominant mood of duration for this phase of the novel is significant for two main reasons:

- The reader gets more engaged in the atmosphere of the novel, since there is no temporal gap between her/him and the story. The reader finds her/himself present next to the characters, and engages in the narrative more effectively as if $\mathrm{s} / \mathrm{he}$ is observing the event in the real world. The created association between the reader and the character clears off the fictionality of the narrative and $\mathrm{s} /$ he becomes one of the members of the conversation, experiencing it more naturally than compared to any other durational moods.

- The use of direct quotes (in dialogue forms) persuades the reader to ascertain that $\mathrm{s} / \mathrm{he}$ is hearing what is said with no reduction or censorship. This certainty mentally assures her/him that her/his evaluation of the event cannot be faulty or manipulated by the narrator, and this is exactly what is intended in chapter IV: to make the reader believe what $\mathrm{s} /$ he reads.

The chapter depicts Dorian and Lord Henry as two poles of innocence and experience, respectively. Lord Henry has no belief in love or its sacredness; for him love is something to happen repeatedly, to change for a difference and for the sake of experience; on the other hand, Dorian, never bowing to Lord Henry's persuasion, strongly believes in love's sacredness and the true nature of his feelings to Sibyl. Here, the reader is once more assured that 
Dorian is truly the innocent creature $\mathrm{s} /$ he has already created in mind. The belief is strongly influenced by the direct and live presentation of a dialogue in which the reader personally observes the strength of love and faithfulness in Dorian.

However, the certainty and belief is astonishingly shattered later, when Dorian turns out to be a god of cruelty as he easily overcomes his conscience, hides his portrait and proceeds to a new investigation of his evil nature. Without giving a prior certainty, especially in chapter IV where the reader is convinced that Dorian is faithful to his love, the intended shock would not occur. This created shock owes its strength to the previous assurance given to the reader by the mood of scene that convinced her/him that s/he personally observed how innocent and humanistic Dorian proved to be in chapter IV.

Summarization: Narrative is a summary by nature, and regardless of the length, summarization is inevitable. It summarizes events like 'waiting for hours' in sentences like 'he waited for hours and hours' which simply takes less that a second for the reader to read. But, deliberate summarizations are always utilized for specific purposes. Among the unique uses of summarization, stands the information provided to the reader through flashback in chapter X, when Dorian unexpectedly shows a brutal manner to Sibyl's suicide and by doing this enters a new phase of his life. At this point, the reader struggles between two opposing poles of an innocent and pure young man. On one hand, Dorian decides to return and ask her to forgive his "completely brutal" reaction, keep distance from Lord Henry and his poisonous theories and devote himself to his lovely future wife; on the other hand, he soon returns to Lord Henry and attempts to forget Sibyl's death keeping himself very indifferent. While the reader is moving between these two conflicting faces of Dorian, the dilemma is aggravated by a summary of his childhood,

He had not entered the place for more than four years - not, indeed, since he had used it first as a play-room when he was a child, and then as a study when he grew somewhat older. It was a large, well-proportioned room, which had been specially built by the last Lord Kelso for the use of the little grandson whom, for his strange likeness to his mother, and also for other reasons, he had always hated and desired to keep at a distance (CW 271).

As already discussed, in this phase, the reader is exposed to a past that appears to be in contrast with what $\mathrm{s} / \mathrm{he}$ has created in mind towards this character. Despite the initial elevated estimations, in this chapter, the reader recognizes a darker side in this bright young man, whose darker side is worsened by a purposeful summary of his problematic childhood. The given summary might be called an 'extra' one, since it directly goes back to his childhood and aims to simply give a hint of a background that seems dark as well. The summary alerts the reader of a new opening side of Dorian that starts to bloom in the coming hideous atmosphere of the novel from this chapter onward. The provided summary functions as an opening gate to the coming new season of Dorian's nature to both himself and the reader as a man who has had a disfavored and gloomy background as well.

Chapter XX, as the final phase of the novel and its shortest chapter, is another example. It opens with "a lovely night" (354) so warm that Dorian did not wear his coat, coming back home, contemplates on his past, his wish, his sins, his murders, and his recent attempts to be good (or to experience goodness). Later he decides to destroy the only sign of his evil deeds, since he realizes that the portrait does not intend to alter for good but get worse and worse even for his apparently good deeds. The scene of stabbing the portrait is suddenly cut and the reader is said about the people around the house and the wakened servants who have heard a horrible cry "in its agony" and entering the locked room, shockingly realize that the borrowed beauty and youth is back to the portrait, while on the floor "was a dead man, in evening dress, with a knife in his heart. He was withered, wrinkled, and loathsome of visage. It was not till they had examined the rings that they recognized who it was" ( $C W 357)$.

The whole chapter takes less than seven minutes to (silent) read from the scene of Dorian walking on the street to the moment he was recognized stabbed on the floor; in this final chapter, a kind of extra summarization is recognizable whose speed leaves the reader alone in an indescribable perplexity and bewilderment. This mental perplexity which lasts for a while as well could not be achieved in any types of duration other than summary. The readers, who have engaged in the story of Dorian Gray, have never been justified for the exchanges between Dorian and the portrait; in fact, the question of this supernatural event is never answered to them. This ambiguity not only remains unanswered in the course of the novel, but also it gets aggravated in the very final moment of the novel, when they are told the portrait transferred back all the burden it had borne for years to Dorian himself, leaving the readers in much more shock. This might be the central reason for Joyce Carol Oates to call this novel a puzzle, "knotted, convoluted, [and] brilliantly enigmatic" (420).

Employing summary has provided the narrator with the opportunity to prune the information as much as he desires and simply depict to the reader an old man who is not like Dorian whom s/he knew. In fact, the created shock owes itself to the use of summary. Moreover, having a look from a very considerable point, Christopher Lane maintains that "the pressure of the unrepresentable acquires an urgent and violent resonance" (936), like summarization, which supports Wilde's awareness of durational types and their appropriate application on the novel.

As it was clarified in each analysis of the three main phases of time (order, frequency, and duration) and their subcategories on the events, it was noted that each specific choice of one type over the other has created a meaningful achievement for the author in order to direct the readers' assumptions towards one particular path, which has certainly achieved its success due to the author's awareness of temporality and its significance about one hundred years prior to 
its proposition by Gérard Genette and the further studies by the more current narratologists like Miek Bal, Gerald Prince, Monika Fludernik, Luc Herman \& Bart Vervaeck, and so many others in the last few years.

The Temporal Function The aim of the present section is to identify and elaborate upon the functions assigned to significant temporal employments running all over Wilde's novel. The profound temporal analysis of the narrative identified three main functions for the temporal employments. These main functions are, a. Ekphrasis, b. Characterization, and $\mathbf{c}$. Reader manipulation.

1. Ekphrasis: Ekphrasis is a general term that refers to "the verbal representation of visual representation" (Mitchell, 152). As the intersection of narrativity and pictoriality, ekphrasis indicates the narrator's attempts to visualize for the reader what he does not see. The temporal descriptions of the novel have firstly changed the written text into a visual one in which the readers are able to mentally visualize the scenes, the characters, and the settings vividly. A prosperous visualization attained from creating a cinematic text within a written one, primarily turns a neutral or even boring reading into a vivid, dynamic, and live performance; instead of becoming passive agents of reading the experience of a narrator, the reader becomes an active observer who directly perceives the characters, the setting, and its significance. This vivid vision has had a great influence on the reader since s/he has somehow "lived" the novel than "read" it.

2. Characterization: A second important function of temporality of the novel lies in the fact that what the reader knows about characters is hardly ever told openly, but is normally wrapped and conveyed in a temporal setting that provides a kind of implicit information in regards to the characters in such organized and rich temporal setting. As Dannenberg asserts, readers, occupied with what they read, are given the information to which they transfer their preoccupied attitudes and feelings. In chapter I of the novel, preoccupied with the fascinating aristocrat atmosphere of Basil's studio and a busy mind that is trying its best to visualize such a luxurious place, the reader also visualizes three gorgeous aristocrat men, whose evaluation not only owes itself to the depicted appearance by the narrator, but also to a great extend results from the elevated setting that had been visualized to her/him. To our surprise, a deep look at the novel shows that the narrator has been too brief in giving such detailed and elaborated descriptions of the characters, their costume, and manners; however, all readers have no doubt a more or less vivid picture and estimation of these characters, and surprisingly suppose that the narrator has provided them with the information. This not only indicates indirect and aesthetical method of characterization, but also shows a kind of manipulative strategy in characterization by which Wilde has been able to arrange the temporal context in such a way that it results in one particular assumption in the reader.

3. Reader manipulation: It was noted in characterization that the reader is rarely given explicit descriptions of the characters' social status, manners, personality, and character. Despite the lack of information on the characters, as the reading starts, the reader immediately starts to create a completely elevated, aristocrat, and fascinating images of Lord Henry Wotton, Basil Hallward, and Dorian Gray (from whom there is only a portrait). While the reader may consider such evaluations resulting from her/his own independent understanding of these characters, temporal consciousness alerts the critical eye of manipulation. Such consciousness indicates that reader normally attribute what s/he read to what follows, no matter the following shares the same quality or not. When no particular information is presented, the character is usually defined based on the setting in which s/he is presented. In fact, in all narratives, more or less, the reader is always under the influence of the narrator, since what $\mathrm{s} /$ he knows is what the narrator wants her/him to know. The narrator hides what is meant to be hidden and reveals what is intended to be revealed. The great exception for this novel lies in the fact that the reader never recognizes the power of such authority in the narrator; the reader believes that her/his understanding of the characters and the events is totally independent and untouched by the narrator, since the impression is that the narrator of the novel never judges the characters and the events at all. This is exactly the key point of this work where the narrator does not intervene with the reader's evaluation directly, but implicitly plays a more highlighted role in doing so by leading their imagination to one particular temporal context whose effect would automatically be transferred to the event or the character presented in that context.

\section{Conclusion}

The findings of the present study indicated Wilde's vigorous awareness of temporality dexterously applying specific temporal features to each event of his work, which has no doubt resulted in the strong temporal foundation for this work. The study not only ascertains the temporal foundation of the work specifically, but also in wider scope, it highlights the art of Wilde's literary composition. It works as a proof that Wilde did not simply take his pen to propagate or publicize his thought; even if so, he was highly aware of temporal design by which he gains the opportunity to direct, lead, mislead, and manipulate his readers.

As noted in the introduction, structural readings of this author's works are valuable sources of investigations that can certainly open new and more objective understandings of his works. One of the suggestions is to lessen the thematic over-emphasis, largely resulting from biased assumptions, and consider the structural significance of Wildean literature. Accordingly, in the present study, the attempt was to dismiss this author from the current culture-bounded criticism and analyze his novel from a more objective point of view opening the space for a better understanding of "Wilde the writer" who has stood the last option to study Wilde giving the front attention to "the gay Wilde" (Small 2000). Further 
narratological investigations of his works can eventually lead us to a structural understanding of this author who should not be limited to thematic or biographical evaluations only.

\section{References}

Bal, Mieke. Narratology: Introduction to the Theory of Narrative (2nd ed). Toronto: University of Toronto Press, 1997. Gigapedia. Web. 05. February 2012.

Bristow, Joseph (ed.). The Complete Works of Oscar Wilde. Vol. III. Oxford: Oxford University Press, 2005.

Chatman, Seymour. Story and Discourse. New York: Cornell University Press, 1978. Bookfi. Web. 30. Sep. 2012.

Fludernik, Monika. An Introduction to Narratology. London: Routledge, 2009. Gigapedia. Web. 8 Feb. 2012.

Genette, Gerard. Narrative Discourse: An Essay in Method. Tran. Jane E. Lewin. New York: Cornell University Press, 1980. Bookfi Library. Web. 05 Oct. 2012.

Herman, Luc, Bart Vervaeck, (written \&trans.). A Handbook of Narrative Analysis. Nebraska: University of Nebraska Press, 2005. Ebooksclub. Web. 18 Aug. 2011.

Gillespie, Michael P. "Ethics and Aesthetics in The Picture of Dorian Gray". Rediscovering Oscar Wilde. Ed. C. George Sandulescu. Barnes \& Noble Imports, 1995. 137-55. The Oscholars Library. Web. 10. Aug. 2011.

---. "Picturing Dorian Gray: Resistent Readings in Wilde's Novel". The picture of Dorian Gray: authoritative texts, backgrounds, reviews and reactions, criticism ( $2^{\text {nd }}$ ed). Ed. Gillespie, Michael P. New York: W.W. Norton \& Co. (2007): 387- 403. Norton Critical Edition. The Oscholars Library. Web. 23 Aug. 2011.

---. "'What's in a name? : Representing The Picture of Dorian Gray". Irishness and (post) Modernism. Ed. John S. Rickard. Lewisburg: Bucknell University Press, 1994. Print.

Lane, Christopher. "Framing Fears, Reading Designs: The Homosexual Art of Painting in James, Wilde, and Beerbohm". The Journal of English History. 61. 4. (1994): 923-54. JSTOR. Web. 02 Dec. 2012.

Oates, Joyce C. "The Picture of Dorian Gray: Wilde's Parable of the Fall". Critical Inquiry. 7. 2 (1980): 419-42. JSTOR. Web. 21 Feb. 2013.

Small, Ian. Oscar Wilde: Recent Research. Greensboro: ELT Press, 2000. 